\title{
ASPECTOS DEFORMACIONAIS EM ESTROMATÓLITOS DO GRUPO ITAIACOCA, A SUL DE ITAPEVA (SP)
}

\author{
WILLIAM SALLUN FILHO ${ }^{1}$, GINALDO ADEMAR DA CRUZ CAMPANHA ${ }^{2}$ \\ $\&$ THOMAS RICHFAIRCHILD ${ }^{3}$
}

\begin{abstract}
Resumo A deformação de estromatólitos foi estudada em metacalcários do Grupo Itaiacoca (Faixa Ribeira), em três localidades ao sul de Itapeva (SP), de forma qualitativa e quantitativa. Dentre as formas identificadas utilizou-se Conophyton para o estudo da deformação por possuir parâmetros iniciais conhecidos. Características distintas entre as formas de Conophyton presentes nas diversas localidades são relacionadas ao ambiente deposicional e a diferenças na preservação, decorrente principalmente da deformação. As lentes e camadas de maior espessura com maior concentração de estromatólitos apresentam melhor preservação. Na pedreira Lavrinhas, os estromatólitos têm margens bem definidas e laminação bem preservada. Mostrou, porém baixo contraste devido à dolomitização/recristalização do metadolomito. Já nos metacalcários calcíticos das pedreiras Indumine/Chiquinho de Barros, a laminação estromatolítica é comumente bem preservada, porém com as colunas deformadas (ondulaclas), demonstrando que reagiram à deformação de maneira mais rígida que o sedimento intercolunar, com movimentação relativa entre elas e desenvolvimento de uma foliação intercolunar. Para os metacalcários dolomíticos de Lavrinhas, o valor médio de $R_{s}$ de 1,34 é compatível aos valores de $R$ entre 1,31 e 1,91 em rochas do Subgrupo Lajeado, a sudeste da região estudada. Em Indumine, o valor de R de 1,91 é mais elevado dò que aqueles encontrados em metacalcários do Subgrupo Lajeado. Deste modo pode-se dizer que o valor de $R$ obtido para os metacalcários dolomíticos pode ser considerado como um valor mais próximo a um valor médio para os metacalcários Grupo Itaiacoca, sendo que o valor de $\mathrm{R}_{\mathrm{s}}$ para Indumine é um valor restrito a esta localidade. As diferenças na deformação entre estes dois tipos litológicos são relacionadas ao comportamento tectônico distinto entre o metacalcário dolomítico (mais puro), com comportamento competente, $\mathrm{e}$ o calcítico (mais argiloso) que atuou de forma mais plástica.
\end{abstract}

Palavras-chave: Estromatólitos, Grupo Itaiacoca, deformação, Conophyton, análise de strain

\begin{abstract}
DEFORMATIONAL ASPECTS IN STROMATOLITES FROM THE ITAIACOCA GROUP, SOUTH OF ITAPEVA (SP) Deformation of stromatolites were studied in metalimestones of the Itaiacoca Group (Ribeira Belt), at three outcrops located on the south of Itapeva, São Paulo, Brazil, with qualitative and quantitative methods. Among the stromatolites identified, we used the Conophyton on the study of the deformation, since the initial parameters are known. Different shape patterns of Conophyton found in several localities are related with the depositional environment and differences of preservation, mainly caused by deformation. The thickest lenses and beds, with larger concentration of stromatolites, are better preserved. In the Lavrinhas quarry, the stromatolites have well-defined margins and well-preserved lamination however the contrast is extinguishes on most samples due to the dolomitization/ recristalization of the metadolostones. Although in the metalimestones of the Indumine/Chiquinho of Barros quarries, the preservation of the stromatolitic lamination is commonly well-preserved, besides the columns are deformed, showing that the columns resisted to the deformation in a more rigid way than the intercolumnar sediment, with relative movements between them. They develop an intercolumnar foliation. The medium value of $R_{s}=1,34$ in the metadolostones of Lavrinhas is similar that the values of $R_{f}$ found in rocks of the Lajeado Subgroup (between 1,31 and 1,91), towards southeast of the analyzed localities. In Indumine the value of $R_{5}$ is higher $(1,91)$ than those found in metalimestones of the Lajeado Subgroup. Therefore, the value of $R_{s}$ obtained for the metadolostones can be considered as a close value to the metalimestone's medium value of the Grupo Itaiacoca, and the value of $R$ of Indumine is a restricted to this locality. The differences according to deformation patterns of these two lithologies are related to the distinct tectonic behavior of the more pure and competent metadolostones than the more argillaceous metalimestones, which has a more plastic
behavior.
\end{abstract}

Keywords: Stromatolites, Itaiacoca Group, deformation, Conophyton, strain analysis

INTRODUÇÃO Estromatólitos são conhecidos em diversas unidades da Faixa Ribeira e ocorrem em abundância em diversas localidades no Grupo Itaiacoca. Foram descritos pela primeira vez no Brasil na região de Itapeva (SP) por Almeida em 1944. Desde então, outros estudos identificaram novas formas e ocorrências (Almeida 1957, Fairchild 1977, Fairchild \& Theodorovicz 1989, Sallun Filho 1999), mas a sua deformação nunca foi abordada em trabalho específico. Diversos trabalhos que trataram de aspectos paleontológicos de estromatólitos que ocorrem em rochas deformadas não consideraram a deformação como um aspecto que po- deria interferir em uma classificação precisa das diversas formas. Este trabalho visa caracterizar e quantificar a deformação dos estromatólitos do Grupo Itaiacoca na região de Itapeva (SP), especialmente das formas de Conophyton e compará-la entre as diversas localidades. A quantificação permite um melhor entendimento sobre a variedade das formas observadas.

Localização A área estudada localiza-se a sul da cidade de Itapeva (SP), folha Ribeirão Branco (SG 22-X-B-II- I, escala 1:50.000), nas proximidades de Nova Campina (SP). As localidades em ques-

1 - Instituto Geológico, Avenida Miguel Stéfano, 390), 04301-9(03, wsallun@uol.com.br, São Paulo, SP

2 - Departamento de Mineralogia e Geotectônica, Instituto de Geociências, USP, Rua do Lago, 562, ginaldo@usp.br, (05508-()80, São Paulo, SP.

3 - Departamento de Geologia Sedimentar e Ambiental, Instituto de Geociências, Instituto de Geociências, USP, Rua do Lago, 562, trfairch@usp.br, 
tão situam-se nas coordenadas (Fig. 1): 717.495, 7329.470-Pedreira Indumine; 718.736, 7330.354 - Pedreira Chiquinho de Barros; 722.568, 7333.029 e 722.434, 7332.990 - Pedreira Lavrinhas (duas frentes abandonadas); 728.933, 7337.041 - Pedreira na Fazenda Santo Antonio.

Contexto Geológico O Grupo Itaiacoca é parte de uma faixa de dobramentos NE-SW que se estende desde a região entre Guapiara e Itapeva (SP) até Itaiacoca (PR). É limitada a noroeste e a sudeste pelos Complexos Graníticos Cunhaporanga e Três Córregos (Neoproterozóico-Eopaleozóico), respectivamente. Os sedimentos paleozóicos da Bacia do Paraná cobrem, em discordância angular e erosiva, os extremos nordeste e sudoeste da faixa de ocorrência do Grupo Itaiacoca, bem como parte do seu limite noroeste, principalmente no estado de São Paulo (Fig. 1).

O Grupo Itaiacoca possui grande variedade litológica, e engloba rochas vulcânicas, siliciclásticas e carbonáticas (Fig. 1). Embora não há uma estratigrafia detalhada do grupo, pode-se reconhecer uma sucessão geral, evidente em diversos trabalhos (Trein $e t$ al. 1985, Theodorovicz et al. 1986; Souza 1990, Reis Neto 1994, Prazeres Filho et al. 1998). Inicia com rochas clásticas seguidas por vulcanossedimentares (bastante variadas), seguidas por rochas químico-pelíticas. Embora ainda não há idade precisa da sedimentação, os dados mais recentes apontam para o Neoproterozóico (Siga Jr. et al. 2003).

As complicações da estratigrafia e da idade de sedimentação do Grupo Itaiacoca refletem, em parte, a complexidade estrutural da região. $\mathrm{O}$ arcabouço estrutural da zona de ocorrência do Grupo Itaiacoca exibe forte orientação NE-SW, com grandes dobras abertas nos pacotes carbonáticos e quartzíticos, e cerradas a isoclinais nos pacotes menos competentes. A vergência estrutural é voltada para NW (Campanha et al. 1987). O metamorfismo destas rochas ocorreu em condições da fácies xisto verde incipiente (Trein et al. 1985, Campanha et al. 1987). A deformação e o metamorfismo teriam sido gerados em ambiente de arco magmático continental (Reis Neto 1994, Campanha \& Sadowski 1999).

Ao final do Neoproterozóico e início do Fanerozóico, diversas falhas e zonas de cisalhamento NE-SW e de caráter transcorrente afetaram toda a área do Pré-Cambriano de São Paulo e Paraná, inclusive a faixa de dobramentos do Grupo Itaiacoca (Campanha \& Sadowski 1999). As falhas podem ter rejeitos quilométricos e muitos dos contatos originais são tectônicos, o que dificulta as reconstituições paleogegeográficas (Campanha et al. 1987).

CARACTERIZAÇÃO DAS OCORRÊNCIAS DE ESTROMATÓLITOS Das nove localidades com ocorrência de estromatólitos a sul de Itapeva, apenas três são tratadas neste trabalho por serem mais significativas e conterem mais dados. As três localidades são as pedreiras Indumine/Chiquinho de Barros, Lavrinhas e da Fazenda Santo Antonio (Fig. 1).

A Pedreira Indumine é ativa e onde afloram metacalcários calcíticos cinza escuros a negros, argilosos e foliados. O metacalcário em explotação é um bioerma envolvido por filitos. Os estromatólitos desta pedreira são, em sua maioria, Conophyton, pequenos em largura (Fig. $2 \mathrm{C}, \mathrm{D}, \mathrm{E}, \mathrm{F}$ ), mas com grande continuidade vertical, podendo algumas colunas ser vistas ao longo de todo o perfil da pedreira (Fig. 5).

A Pedreira Chiquinho de Barros tem duas frentes de lavra abandonadas, situadas a $1,5 \mathrm{~km}$ de Indumine. Nesta, aflora o mesmo tipo de rocha de Indumine, sendo uma continuidade do mesmo bioerma. Atualmente, a vegetação cobriu a Pedreira Chiquinho de
Barros impossibilitando a observação dos estromatólitos. As amostras da Pedreira Chiquinho de Barros foram coletadas por T.R. Fairchild na década de 1970. Para a análise da deformação, a Pedreira Indumine e a Pedreira Chiquinho de Barros foram agrupadas.

A Pedreira de Lavrinhas possui uma frente ativa e duas abandonadas, estas com estromatólitos. Afloram metacalcários dolomíticos cinza claros, com Conophyton (Figura 2B) e outras formas não-cônicas ramificadas. A visualização dos estromatólitos nesta pedreira é difícil, pois a laminação foi apagada por intemperismo.

A Pedreira na Fazenda Santo Antonio é uma frente abandonada com metacalcário dolomítico silicoso bandado, preto, branco e vermelho, explotado como rocha ornamental (Fig. 6). As frentes consistem de dois cortes verticais de até $15 \mathrm{~m}$ de altura.

\section{CARACTERIZAÇÃODASFORMASDEESTROMATÓLITOS} Apenas Conophyton foi utilizado para o estudo da deformação, pois possui parâmetros pré-deformacionais conhecidos, como o contorno circular em corte transversal (Fig. 9C)_e laminação cônica em corte longitudinal (Fig. 2B e C). As formas não-cônicas também foram deformadas, porém não utilizadas, pois sua forma original não é bem determinada. Estes parâmetros e a presença de uma zona axial, que consiste em um feixe central formado pelo empilhamento das pontas das sucessivas lâminas cônicas, caracterizam o grupo Conophyton (Fig. 2B e E) e que estão presentes nas formas estudadas e em todas as localidades analisadas.

As colunas se apresentam agregadas, formando estruturas

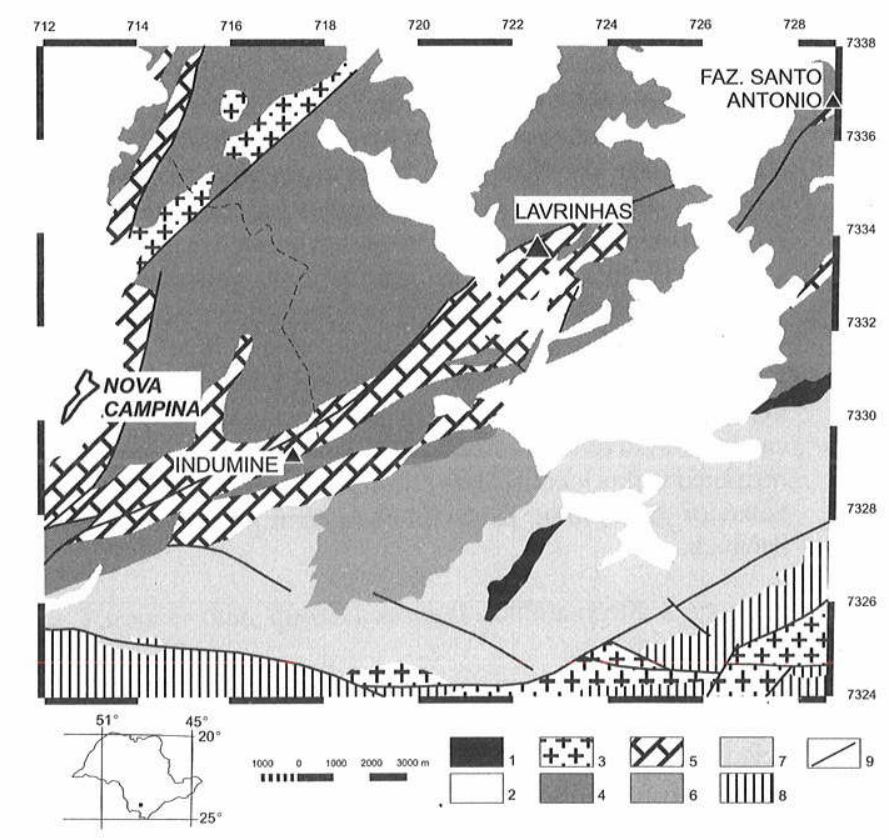

Figura 1 - Mapa geológico da área de estudos com as ocorrências analisadas (Modificado de Theodorovicz et al. 1986). 1- Aluviões (Quaternário); 2-Sedimentos da Bacia do Paraná(Paleozóico); 3- Granitos intrusivos (Neoproterozóico a Cambriano); Faixa Itaiacoca (Meso-ou Neoproterozóico): 4- Metassedimentos Clásticos, 5- Metacalcários, 6Metavulcânicas, 7- Metassedimentos Clásticos e de procedência vulcanogênica; 8-Complexos metamórficos (Meso- a Peleoproterozóico); 9- Falhas principais. 
compostas por colunas de diversos tamanhos, as quais podem coalescer (mais comum em Lavrinhas) (Fig. 9), e contornos poligonais (Fig. 2A). O espaço intercolunar é pequeno e varia de 0,5 a $2 \mathrm{~cm}$ (deformado) (Fig. 2A).

As formas estudadas possuem contorno original circular em corte transversal, com diâmetros maiores em Lavrinhas (10 a 30 $\mathrm{cm})$, e menores em Indumine $(6 \mathrm{a} 10 \mathrm{~cm})$ e na Faz. Santo Antonio (até $10 \mathrm{~cm}$ ) (Fig. 9). O ângulo apical médio deve ter sido em torno $45^{\circ}$ calculado graficamente (Fig. 2B). O relevo sinótico varia de acordo com o diâmetro da coluna, e quanto maior o diâmetro da coluna maior o relevo sinótico, até ocasionalmente ultrapassar o próprio diâmetro. Foram observados exemplares com $60 \mathrm{~cm}$ de
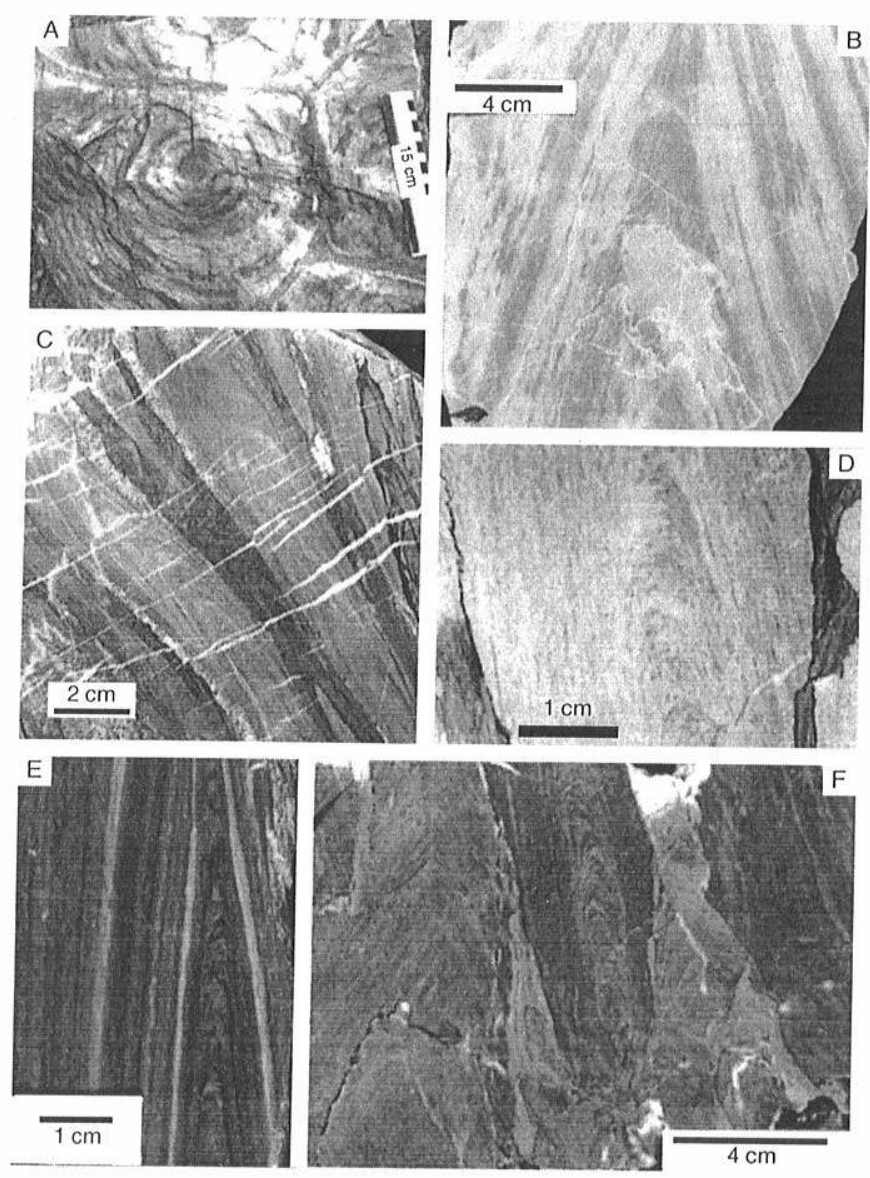

Figura 2 - Fotos de estromatólitos de Lavrinhas e Indumine. A-Colunas em corte transversal exibindo margens bem definidas e contorno poligonal (original). B-Conophyton com laminação cônica evidente. C-Colunas estiradas com laminação cônica acentuada pela deformação. As margens das colunas exibem recristalização, no contato com o sedimento intercolunar. D- Lâmina petrográfica de uma coluna da amostra da figura $2 F$, com laminação mal definida, margens irregulares e sedimentos argilosos entre as colunas. E- Coluna com zona axial evidente e ângulo apical acentuado pela deformação. F- Colunas com laminação cônica e zona axial evidente. Observe o estreito espaço intercolunar preenchido por sedimentos argilosos. A duas colunas localizadas a esquerda na foto chegam a se tocar na parte superior (Fig. 2D). relevo sinótico, onde o diâmetro era de $60 \mathrm{~cm}$. A zona axial é geralmente estreita, com 3 a 4 mm de largura média (Fig. 2E).

A laminação é milimétrica a submilimétrica, mal preservada em Lavrinhas devido à recristalização (inexistente em alguns pontos) (Fig. 2B), e melhor definida em Indumine (Fig. 2E) e na Faz. Santo Antonio.

Outros detalhes sobre a morfologia dos estromatólitos analisados estão descritos em Fairchild (1977), Sallun Filho (1999) e Sallun Filho \& Fairchild (2004).

ASPECTOS DEFORMACIONAIS A deformação no Grupo Itaiacoca agiu de maneira diferenciada de acordo com as características e a competência de cada litotipo. Por exeplo, os metacalcários do Grupo Itaiacoca deformaram-se de forma mais rígida e menos dúctil do que rochas menos competentes (p.ex., metapelitos). Assim, de modo geral, eles contém grandes dobras abertas, estruturas rúpteis (fraturas, falhas, etc.) e a se recristalizar. Excepcionalmente ocorrem dobras apertadas, intensa recristalização ou milonitização em zonas de falha.

Outras tipos litológicos, como metarenitos e metacherts, exibem comportamento estrutural semelhante, enquanto as rochas menos competentes, como metapelitos e certas rochas vulcânicas, estão intensamente foliadas e dobradas.

A área estudada foi severamente deformada, mas graças à competência dos calcários em relação aos metapelitos, muitos estromatólitos resistiram à deformação, embora não incólumes. As lentes e camadas de maior espessura (métrica) e maior concentração de estromatólitos (bioermas/biostromas) apresentam melhor preservação (p. ex., Lavrinhas e Indumine), apesar da perda de nitidez da laminação nos metacalcários dolomíticos (Lavrinhas) e a deformação dúctil mais intensa nos metacalcários calcíticos (Indumine).Em geral, estes corpos não apresentam acamamento plano-paralelo interno original devido á orientação variada das colunas e domos que os constituem, o que empresta ao bioerma/ biostroma um caráter maciço e compacto, ao contrário da estrutura acamadada típica da grande maioria das rochas sedimentares. Camadas e lentes de estromatólitos mais finas, sujeitas à mesma deformação, perderam suas estruturas sedimentares mais facilmente. Assim, dentro dos próprios metacalcários, observa-se uma preservação diferenciada, devido às diferenças reológicas perante a deformação.

Em Lavrinhas, os estromatólitos tem margens bem definidas e laminação bem preservada, porém de baixo contraste, devido à dolomitização/recristalização (Fig. 2A). As porções mais escuras dos estromatólitos representam trechos com laminação foi preservada (Fig. 2B). Os metacalcários tiveram uma deformação mais rígida e rúptil devido à sua maior pureza e consequiente maior competência.

Já em Indumine e Chiquinho de Barros a preservação da laminação estromatolítica varia de bem preservada (Fig. 2E) a quase totalmente apagada com intensa recristalização. As colunas estão deformadas (onduladas) (Fig. 2C), pois são de calcários mais puros do que os sedimentos intercolunares mais impuros e menos competentes. Assim, as colunas reagiram à deformação de de fora mais rígida que o sedimento intercolunar, com movimentação relativa, demonstrada por truncamento apenas de um lado das colunas e recristalização das margens, o que resultou em quase desaparecimento dos sedimentos intercolunares e dobramento das colunas (Fig. 2C, D, F). A orientação de minerais argilosos (foliação) entre as colunas evidencia sua deformação mais dúctil (Fig. 2D). As colunas maiores foram menos deformadas que as menores, 
como registrado pela quantificação da deformação.

A Pedreira Lavrinhas expõe uma estrutura sinformal (Fig. 3) e as ocorrências de estromatólitos se situam no seu flanco sudeste. A dobra tem eixo N30E/50 e a zona de charneira aflora na frente da pedreira (Fig. 3). A orientação do eixo das colunas dos estromatólitos é S20W com caimento de $40^{\circ}$ e topo voltado para NE. A atitude da estratificação dos metacalcários é N40-50E, 70-80 NW (Fig. 4A). O ângulo entre o eixo das colunas dos estromatólitos e a estratificação é, portanto, de cerca de $30^{\circ}$, valor distinto do original de $90^{\circ}$. A direção das colunas é, aparentemente, perpendicular ao eixo da sinforma (Fig. 4A).

Em Indumine ocorrem metacalcários calcíticos compostos apenas por estromatólitos, sendo muito difícil observar estratificação. Nas laterais da pedreira, abaixo dos metacalcários ocorrem filitos que, aparentemente, desenham dobra sinformal de eixo N50E/13, como observado por Theodorovicz et al. (1986) (Figs. 3 e 4B). Mas nas laterais SW e NW da pedreira também ocorrem metacalcários intercalados nestes filitos, com camadas de direção contrária a da sinforma. Uma explicação para este fato é que os metacalcários de Indumine e Chiquinho de Barros teriam forma lenticular de direção NE-SW, gerada por deformação diferencial entre os filitos e os metacalcários. Alternativamente, esta forma pode refletir a geometria original do bioerma. A orientação dos estromatólitos dentro dos metacalcários é marcante, com as colunas na foliação orientada segundo N50-60E/80NW. Os eixos das colunas caem $4^{\circ}$ para SW e os topos estão voltados para NE (Fig. 4B). A foliação se formou entre as colunas, mas se desenvolveu mais em algumas porções com aspecto amendoado, provavelmente aproveitando espaços maiores entre clunas agrupdas (Fig. 5).

A Faz. Santo Antonio é um caso particular, pois os metacalcários dolomíticos são, pelo menos em parte, tectonicamente bandados, com bandas pretas, brancas e vermelhas, intensamente deformadas e recristalizadas. As vermelhas estromatolíticas menos recristalizadas formam boudins dentro de camadas deformadas. Nas bordas dos boudins, fragmentos estirados de estromatólitos penetram as faixas mais deformadas. A orientação do bandamento é N65E/65SE, com indicadores cinemáticos (sigmóides compostos pelos próprios estromatólitos estirados) de movimentação sinistral. Ocorrem porções brancas com textura grossa devido à recristalização por deformação, por vezes cortando o bandamento.

Especula-se que as camadas mais deformadas podem representar horizontes originais plano-laminados, talvez estromatólitos estratiformes, ou mais impuros (argilosos), o que proporcionaria deformação mais plástica do que nas camadas de estromatólitos colunares. Poderia ter havido, ainda, uma organização planar maior neste caso do que em Lavrinhas e Indumine. Mesmo assim a deformação nesta localidade parece ter sido muito mais intensa do que nas outras localidades, aproximando-se do limite para a preservação dos estromatólitos.

Análise quantitativa Para comparar quantitativamente a deformação nos metacalcários de Indumine com os de Lavrinhas, foram calculadas as razões de strain, ou seja, a razão entre os eixos maior e menor da elipse de strain (deformação finita). Na Faz. Santo Antonio não foi possível realizar esta análise. O pressuposto do método foi de que as seções perpendiculares às colunas dos estromatólitos (seções transversais) eram, na origem, aproximadamente circulares ou, no máximo, ligeiramente elípticas (Fig. 9). Desse modo obtém-se a elipse de strain relativa ao plano da estratificação original. Adotou-seo método proposto por Ramsay \& Huber (1993) que se baseia em: a) medidas de eixo maior e menor

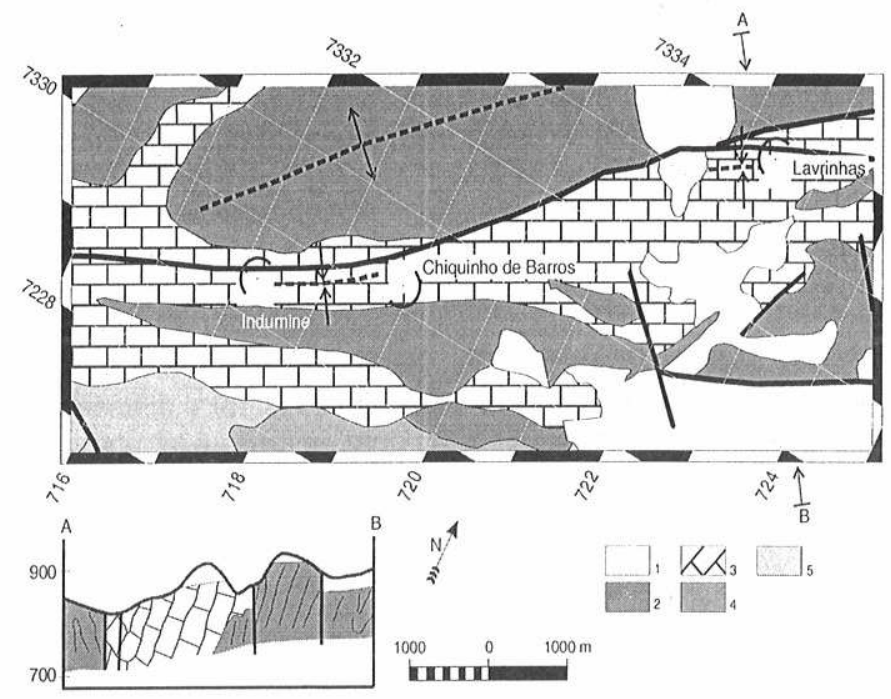

Figura 3 - Mapa da situação geológico-estrutural de Lavrinhas e Indumine. Modificado de Theodorovicz et al. (1986). 1 - Sedimento da Bacia do Paraná, Faixa Itaiacoca, 2 - Metassedimentos blásticos, 3 - Metacalcários, 4 Metavulcânicas , 5-Metassedimentos blásticos e de procedência vulcanogênica.
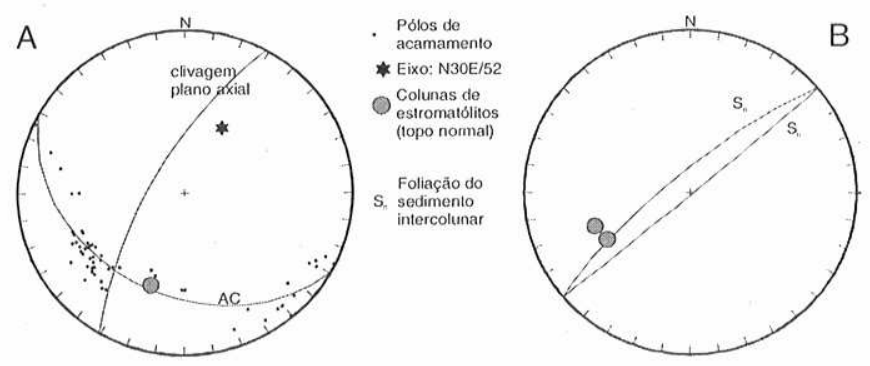

Figura 4 - Estereogramas das pedreiras Lavrinhas (A) $e$ Indumine $(B)$.

das elipses; b) cálculo da elipsidade $\left(\mathrm{R}_{\mathrm{f}}\right)$ de cada objeto deformado de acordo com a equação (1); c) cálculo da razão de $\operatorname{strain}\left(\mathrm{R}_{\mathrm{s}}\right)$ por meio da média harmônica dos $\mathrm{R}_{\mathrm{f}}$.

$$
R_{f}=\frac{\text { eixo maior }}{\text { eixomenor }}
$$

Ramsay \& Huber (1993) mostram que a aplicação da média harmônica dos valores de elipsidade observada nos objetos deformados tem a vantagem de ser procedimento mais simples e fornece valores de razão de strain $\left(R_{s}\right)$ mais próximos dos obtidos pelo método $\mathrm{R} / \varnothing$ utilizado para medir a razão de strain de objetos originalmente elípticos, baseado na razão entre a elipsidade $\left(R_{\mathrm{r}}\right)$ e a orientação das elipses $(\varnothing)$.

Para Indumine utilizaram-se 58 medidas de eixo maior e eixo menor de colunas de estromatólitos em corte perpendicular ao eixo das colunas, tomadas em amostras, em afloramentos e a partir de fotografias. Os valores de $R_{t}$ calculado em Indumine variam entre de 1,13 e 5,67, com $\mathrm{R}$ igual a 1,91. Também em Indumine foi aplicado o método de Fry (1979) para obtenção de R, baseado na 
distribuição dos centros das elipses vizinhas, a partir de uma fotografia de colunas em seção transversal em afloramento.

Por este método obteve-se $R$ igual a 2,15 mostrando graficamente a forma e a orientação da elipse média (Fig. 7C). O eixo maior da elipse está contido no plano da foliação e se posiciona na sua direção N50E. O valor de $\mathrm{R}_{\mathrm{s}}$ por este método é um pouco maior que o $\mathrm{R}_{\mathrm{s}}$ obtido pela média harmônica das elipsidades calculadas para a Indumine. Isto se explica pela deformação nos espaços entre as colunas, ocupados por sedimento argiloso, ter sido maior que a deformação das colunas, já que o método centro a centro Fry (1979) registra predominantemente a deformação da matriz entre os objetos, se estes forem mais competentes que a matriz, e o das elipsidades registra a deformação das colunas.

Em Lavrinhas, a medição dos estromatólitos foi difícil devido ao grande tamanho das colunas de Conophyton e a forma originalmente alongada das não-cônicas ramificadas. Desta forma utilizaram-se 50 medidas de eixo maior e eixo menor de uma amostra com oólitos da região de Bom Sucesso (SP), a cerca de $35 \mathrm{~km}$ a sudeste da área estudada. Apesar da distância, estes dados foram utilizados para comparação, admitindo uma deformação semelhante nos metacalcários dolomíticos da região estudada. Nos oólitos os valores de $\mathrm{R}_{\mathrm{r}}$ variam entre 1 e 3,5, com $\mathrm{R}_{\mathrm{s}}$ igual a 1,34 .


Figura 5 - Estromatólitos da Pedreira Indumine. A e B-Fotografia e desenho de estromatólitos deformados com plano de foliação do lado esquerdo do afloramento. Notar o aspecto "amendoado" das colunas. C e D-Vista lateral e frontal de colunas deformadas, mostrando a foliação intercolunar e o pequeno espaço existente entre as colunas.
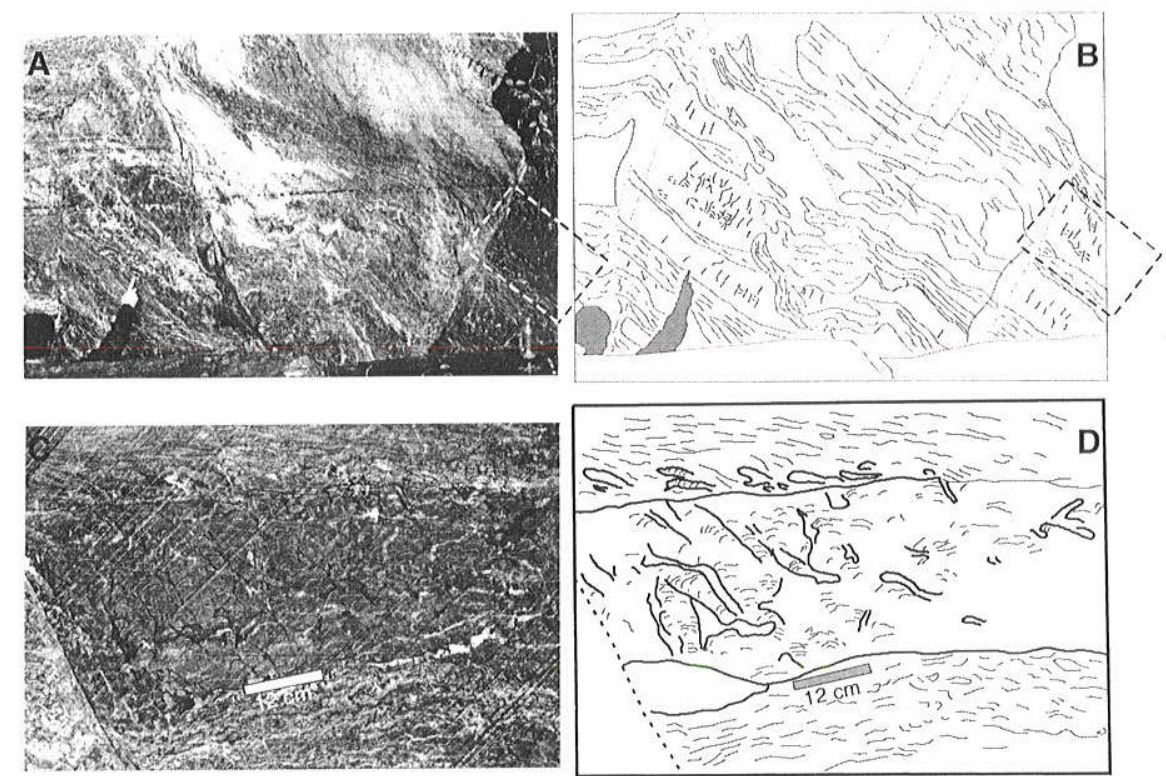

Figura 6-Estromatólitos da Fazenda Santo Antonio. A e B-Fotografia e desenho esquemático de uma visão geral do afloramento. $O$ retângulo representa as figuras $6 C$ e D. C e D-Fotografia e desenho esquemático de um boudin estromatolítico (a escala corresponde a $13 \mathrm{~cm}$ ). 
Assim os valores de $\mathrm{R}$ obtidos nos estromatólitos de Indumine são maiores que os obtidos pela da análise dos oólitos deformados, considerados como semelhantes aos de Lavrinhas. Os valores de deformação finita podem ser considerados baixos em Lavrinhas e moderados em Indumine.

Estes métodos avaliam a deformação das colunas em corte transversal, mas observa-se que algumas características internas também mostram esta deformação e podem ser quantificadas. Uma das características que foram alteradas pela deformação é o relevo sinótico, o qual corresponde à medida da altura do "ponto mais alto" da laminação utilizada na caracterização de estromatólitos. O ângulo entre a laminação em corte longitudinal axial é chamado de "ângulo apical". Quando o ângulo apical é menor que o original, o valor do relevo sinótico deve ser maior que o original. O cálculo de

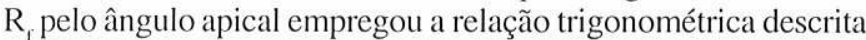
na Figura 8 e pela equação 2.

$$
\begin{aligned}
& \operatorname{tg}(a 1 \div 2)=x \div d \\
& \text { Como, } \mathrm{R}_{\mathrm{f}}=\mathrm{x} \div \mathrm{y} \\
& \operatorname{tg}(\mathrm{a} 2 \div 2)=\mathrm{y} \div \mathrm{d} \\
& \mathrm{R}_{\mathrm{r}}=(\operatorname{tg}(\mathrm{a} 1 \div 2)) \div(\operatorname{tg}(\mathrm{a} 2 \div 2)) \\
& x \div y=(\operatorname{tg}(a 1 \div 2)) \div(\operatorname{tg}(a 2 \div 2))
\end{aligned}
$$

Em Lavrinhas, o ângulo apical médio ( 8 medidas) é de $60^{\circ}$ no eixo maior e $40^{\circ}$ no menor, indicando uma razão de strain de 1,58. Em Indumine o ângulo apical médio é de $40^{\circ}$ no eixo maior e $20^{\circ}$ no menor, indicando razão de strain de 2,06. Além disso, em Lavrinhas, assuindo que as colunas dos estromatólitos eram originalmente circulares e que não ocorreu muita mudança no volume, o ângulo apical original, calculado graficamente (Fig. 8), era de aproximadamente $50^{\circ}$. Desta forma, admitindo que as formas coniformes em Indumine eram semelhantes às de Lavrinhas, os ângulos apicais nas formas de Indumine foram diminuídos por achatamento das colunas paralelamente à estraficiação durante a deformação. Em Chiquinho de Barros o achatamento foi extremo, chegando a formar ângulos de até $15^{\circ}$ no eixo menor. Estas mudanças de ângulos apicais indicam que o relevo sinótico também foi alterado.

Assim como nos estromatólitos cônicos, as demais formas também foram deformadas. Isto se reflete nas formas não-cônicas por achatamento, e conseqüente aumento das elipsidades das colunas e da convexidade da laminação. Em alguns casos a laminação é parabólica, que pode ser um efeito da deformação.

Outro método para obtenção de $\mathrm{R}_{\mathrm{r}}$ utiliza a relação angular atual entre as colunas e o acamamento, assumindo uma relação original (indeformada) de $90^{\circ}$. O método é descrito por Ramsay \& Huber (1993) e utiliza o ângulo de cisalhamento (f) das colunas com o acamamento e a relação com a deformação principal de

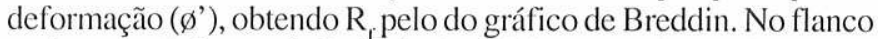
sudeste da sinforma da Pedreira Lavrinhas, as colunas fazem um ângulo de $30^{\circ}$ com a estratificação (Fig. 4A), ou seja, uma deformação cisalhante ocorreu no plano que contém as colunas e é normal ao acamamento. Assim fé de $-60^{\circ}$ (negativo devido à convenção, Ramsay \& Huber, 1993). Como ostra a figura 4A, as colunas estão contidas no plano $\mathrm{AC}$ da dobra e formam um ângulo de $16^{\circ} \mathrm{com}$ a clivagem plano-axial, que representa $\varnothing^{\prime}$. Com estes dados, pelo gráfico de Breddin obtém-se um valor de $\mathrm{R}_{r}$ de 4,0. Este método avalia a elipsidade medida no plano de acamamento enquanto os deais valeram-se do corte perpendicular às colunas, nem sempre coincidentes. Isto explica os valores mais elevados do que os obtidos anteriormente.

Em Indumine, a deformação foi mais intensa nas colunas de menor diâmetro e vice-versa. Esta suspeita observada a princípio visualmente, foi posteriormente testada pela relação entre o diâ- metro original e as respectivas elipsidades $\left(R_{\mathrm{r}}\right)$, anteriormente obtidas. O diâmetro original dos estromatólitos foi calculado, com base em Davis \& Reynolds (1996), sob a premissa de objetos originalmente circulares e de não ter havido variação de área na seção medida, utilizando as equações (3).

$$
\begin{aligned}
& \text { П.a. } b=\Pi \cdot r^{2} \Rightarrow r^{2}=a \cdot b \Rightarrow r=\sqrt{a \cdot b} \\
& \text { 2. } r=\text { diâmetro }
\end{aligned}
$$

Pela figura 10 observa-se que, em geral, as colunas maiores, principalmente as de diâmetro superior a $15 \mathrm{~cm}$, estão menos deformadas, enquanto as menores estão mais deformadas.

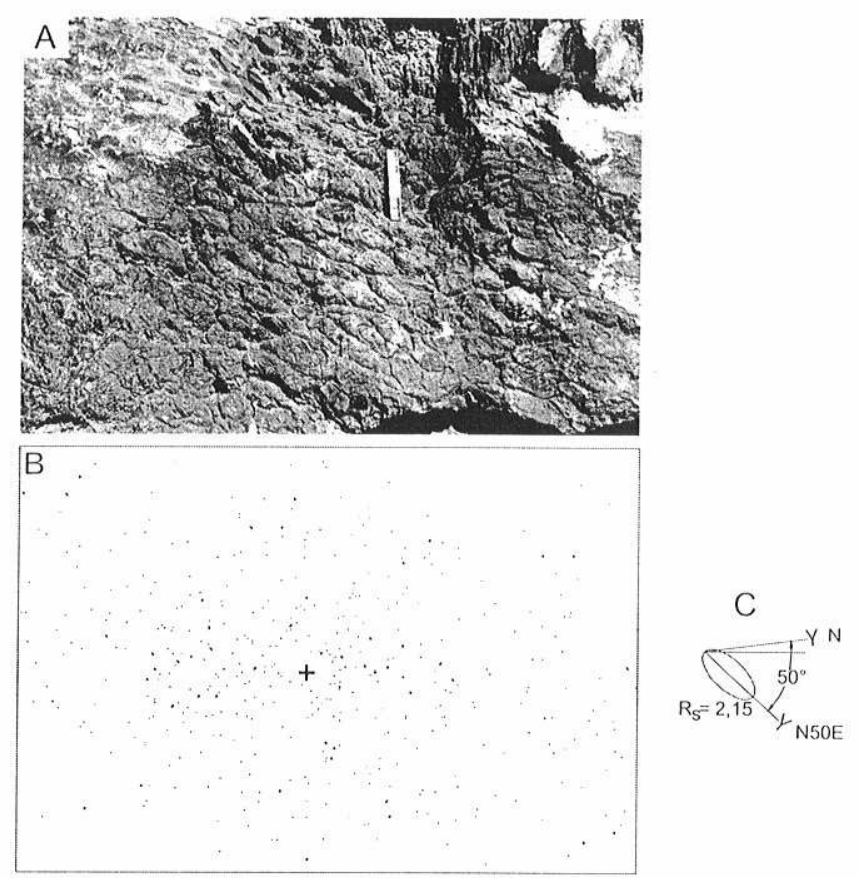

Figura 7 - Aplicação do método de Fry (1979) em estromatólitos da Pedreira Indumine. A- Fotografia do afloramento com colunas em corte transversal. B-Diagrama final mostrando a distribuição dos pontos compostos pelos centros das elipses das colunas de estromatólitos da fotografia A, formando uma elipse no centro da figura. C-Elipse gerada pelo diagrama final $(B)$ com o respectivo valor de $R s$ e de orientação.

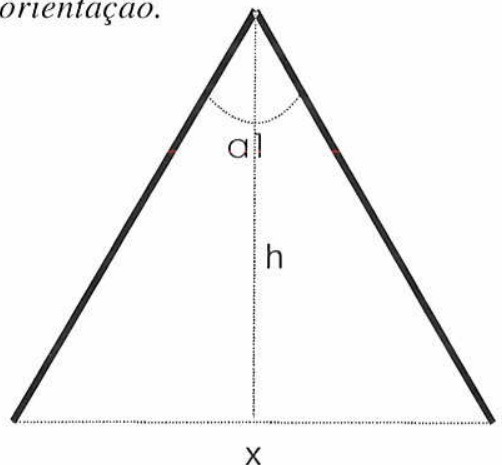

eixo maior

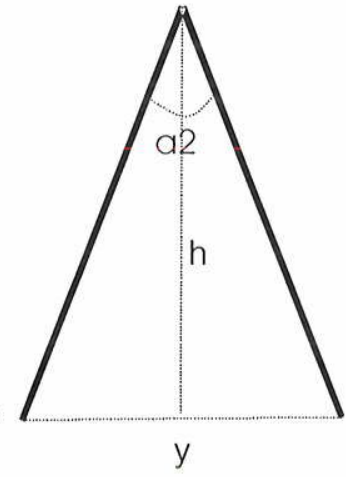

eixo menor
Figura 8 - Parâmetros geométricos utilizados para calcular o $R_{f}$ a partir do ângulo apical, onde $h=$ altura, $a l=\hat{a}$ anulo medido no eixo maior, a2 = ângulo medido no eixo menor, $x=$ comprimento do eixo maior e $y=$ comprimento do eixo menor. 
A influência da composição na deformação Como visto, estromatólitos ocorrem tanto em metacalcários dolomíticos quanto em calcíticos, com predomínio nos primeiros. A diferença na deformação observada nos estromatólitos das diversas localidades está intimamente relacionada com a composição da rocha. Destaca-se a questão da pureza do calcário em relação a resíduos insolúveis (não-carbonáticos).

A dissolução do metacalcário dolomítico de Lavrinhas resulta em resíduo silicoso branco, e quantidade menor nas colunas $(1,5 \%)$ do que no sedimento intercolunar (4,5\%). Análises químicas mostraram que as colunas são formadas por calcário dolomítico quase puro, e assim $\mathrm{Si}$ e $\mathrm{Al}$ são raros ou inexistentes nestas.

O metacalcário calcítico de Indumine é facilmente solúvel e resulta em resíduo escuro de material argiloso e pequena quantidade de matéria orgânica, que flutua na solução. A quantidade de resíduo nas colunas $(10 \%)$ é menor do que no sedimento intercolunar (13\%), onde pode atingir até $50 \%$. Análises químicas mostraram que as colunas são compostas por calcário calcítico puro, com pouca Si e Al, e o sedimento intercolunar por material argiloso com carbonato, com 20 a $30 \%$ de Si e 8 a $15 \%$ de Al.

O metacalcário dolomítico de Faz. Santo Antonio é de difícil dissolução e o resíduo é bastante silicoso. As porções estromatolíticas (bandas avermelhadas) possuem menos impurezas que as pretas e brancas entre as camadas estromatolíticas, cerca de $17 \%$ e $43 \%$ respectivamente. Análises químicas evidenciaram baixos teores de carbonatos nos estromatólitos e camadas entre eles. Altos teores de Si ocorrem em ambas partes, com cerca de $25 \%$ nos estromatólitos e $50 \%$ nas camadas não estromatolíticas.

Os metacalcários dolomíticos de Lavrinhas são em geral mais puros do que os calcíticos de Indumine e Chiquinho de Barros. Em Faz. Santo Antonio as bandas avermelhadas são mais puras e as pretas e brancas mais impuras. Em rocha total, há maior quantidade de resíduo insolúvel na Faz. Santo Antonio, seguido de Indumine e de Lavrinhas.

CONCLUSÕES O uso de estromatólitos como indicadores de deformação se mostrou satisfatória, principalmente quando ocorrem formas cônicas, como Conophyton. Sem dúvida há limitações para seu uso, mas os resultados são satisfatórios especialmente na comparação entre as diversas localidades. As diferenças entre os tipos de Conophyton dos metacalcários do Grupo Itaiacoca estão relacionadas a aspectos deposicionais e de preservação, principalmente devido à deformação, a qual teve papel importante no aspecto final dos tipos de Conophyton observados.

Qualitativamente, muitas diferenças entre as formas presentes nos metacalcários dolomíticos e calcíticos foram observadas desde o início dos estudos, que posteriormente foram confirmadas pela análise quantitativa.

Nos metacalcários dolomíticos, o valor médio de $\mathrm{R}$ de 1,34 (de 1 a 3,5) é semelhante aos valores de R 1,31 a 1,91 (até 2,30 e 2,79 próximo às zonas de falha) encontrados por Campanha (1991) e Campanha \& Sadowski (2002) em rochas do Subgrupo Lajeado, a sudeste da região estudada. Os valores mais elevados obtidos por aqueles autores devem-se ao fato de que se trata de medidas extraídas tanto de rochas terrígenas quanto de carbonáticas. Em Indumine, o valor de $\mathrm{R}_{\mathrm{s}}$ de 1,91 é mais elevado que os encontrados em metacalcários do Subgrupo Lajeado obtidos por Campanha (1991). Deste modo, o valor de R 1,34 obtido em oólitos pode ser considerado como o mais próximo da média nos metacalcários do Grupo Itaiacoca, e o valor de $\mathrm{R}_{\mathrm{s}}$ em Indumine é restrito a esta localidade.
De forma geral as diferenças na preservação dos estromatólitos podem ser relacionadas a comportamentos tectônicos distintos entre o metacalcário dolomítico (mais puro), com comportamento competente, da Pedreira Lavrinhas e o calcítico (mais argiloso) que atuou de forma mais plástica, na Pedreira Indumine.

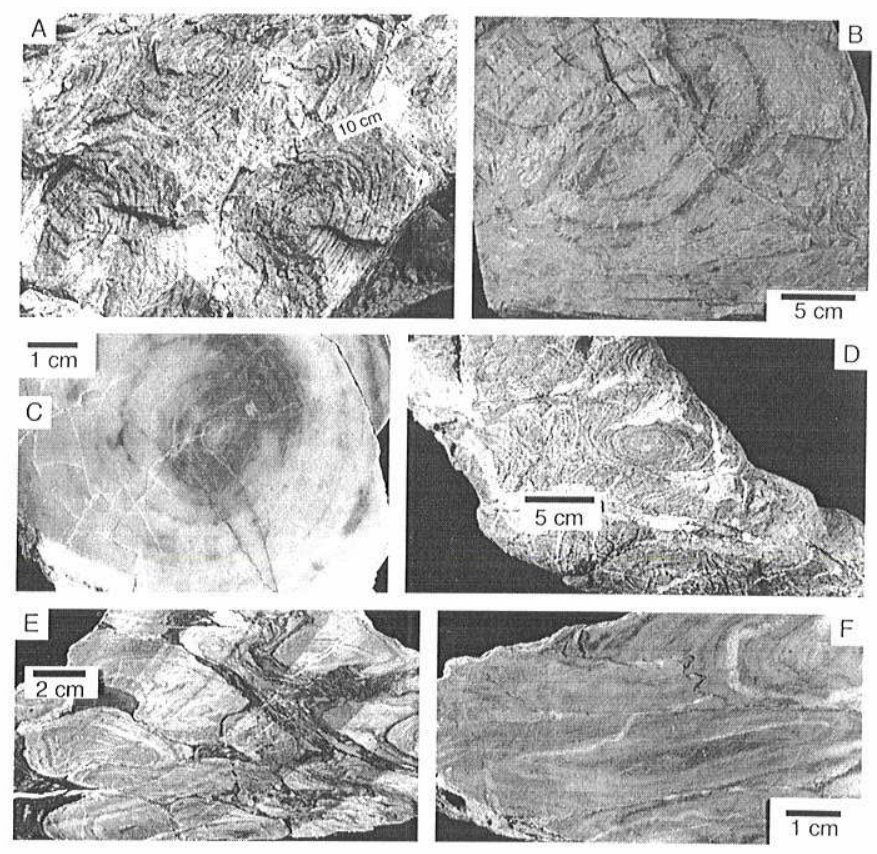

Figura 9 - Fotos de colunas de estromatólitos em corte transversal. A e B-Colunas de contornos elípticos, com pequeno espaço intercolunar. Pedreira Lavrinhas. C-Coluna de contorno circular, praticamente não deformada. Pedreira Lavrinhas. D-Colunas de contornos elípticos, com pequeno espaço intercolunar. Pedreira Indumine. E- Colunas deformadas exibindo contornos irregulares, com espaço intercolunar muito pequeno ou ausente. Pedreira Indumine. $F$ - Coluna de contorno elíptico muito deformada, com razão de strain de 5,67.



Figura 10 - Relação das elipsidades $\left(R_{\text {f }}\right.$ com os diâmetros originais teóricos, para cada coluna medida em Indumine. 
Agradecimentos À FAPESP pelo financiamento das pesquisas. Às companhias Cimento Portland Itaú, da Pedreira Lavrinhas, e Cimento Portland Maringá, atual Minas Oeste, da Pedreira
Indumine, sempre prestativos e atenciosos nas visitas às pedreiras. Aos relatores da RBG pelas sugestões apresentadas ao manuscrito.

\section{Referências}

Almeida F.F.M. de 1944. Collenia itapevensis sp. n. - um fóssil précambriano do Estado de São Paulo. Boletim da Faculdade de Filosofia, Ciências e Letras Universidade de São Paulo XLV, Geologia, 1:89-106.

Almeida F.F.M. de 1957. Novas ocorrências de fósseis no pré-cambriano brasileiro. Anais da Academia Brasileira de Ciências, 29:63-72.

Campanha G.A. da C. 1991. Tectônica proterozóica no alto e médio Vale do Ribeira, estados de São Paulo e Paraná. Tese de Doutoramento, Instituto de Geociências, Universidade de São Paulo, $295 \mathrm{p}$.

Campanha G.A. da C., Bistrichi C.A., Almeida M.A. 1987. Considerações sobre a organização litoestratigráfica e evolução tectônica da faixa de dobramentos Apiaí. In: SBG, Simp. Sul-brasileiro de Geologia, 3, Atas, 2:725-742.

Campanha G. A. da C. \& Sadowski G. R. 1999.Tectonics of the southern portion of the Ribeira Belt (Apiaí Domain). Prec. Res., 98:31-51.

Campanha G. A. da C. \& Sadowski G. R. 2002. Determinações da deformação finita em rochas metassedimentares da Faixa Ribeira na região de Iporanga e Apiaí, SP. Rev. Bras. Geoc., 32(1):107-118.

Davis G.H. \& Reynolds S.J. 1996. Structural geology of rocks and regions. Wiley, $776 \mathrm{pp}$.

Fairchild T.R. 1977. Conophyton and other columnar stromatolites from the Upper Precambrian Açungui Group near Itapeva, SP, Brazil. In: SBG, Simp. Reg. de Geologia, 1, Atas, p. 179-198.

Fairchild T.R. \& Theodorovicz. A. 1989. Novas ocorrências de estromatólitos no Grupo Itaiacoca (Proterozóico médio a superior), sul do Estado de São Paulo. In: SBP, Cong. Bras. de Paleontologia, 11, Resumos, p. 4.

Fry N. 1979. Random point distributions and strain measurement in rocks. Tectonophysics, 60:89-105.

Prazeres Filho H., Guimarães G., Basei M., Siga Jr., Reis Neto J.M. dos, Campanha G., Sallun Filho W. 1998. Mapa geológico 1:50.000 da porção centro-sul da Faixa Itaiacoca - PR. In: SBG, Congr. Bras. Geol., 40, Ancis, p. 36.
Ramsay J.G. \& Huber M.I. 1993. The techniques of modern structural geology - Volume 1: Strain Analysis. Academic Press, 307 pp.

Reis Neto J.M. dos 1994. Faixa Itaiacoca: registro de ama colisão entre dois blocos continentais no Neoproterozóico. Tese de Doutoramento, IG/USP, $253 \mathrm{p}$.

Sallun Filho W. 1999. Análise dos estromatólitos do Grupo Itaiacoca (Proterozóico)), ao sul de Itapeva, SP. Dissertação de Mestrado, IG/ USP, $126 \mathrm{p}$.

Sallun Filho W. \& Fairchild T.R. 2004. Estromatólitos do Grupo Itaiacoca ao sul de Itapeva, Estado de São Paulo, Brasil. Rév. Bras. Paleontologia, 7(3):359-370).

Siga Jr., O., Basei M.A.S., Sato K., Prazeres Filho H.J. dos, Cury L.F., Weber W., Passarelli C.R., Harara O.M., Reis Neto J.M. dos 2003. U-Pb (Zircon) ages of metavolcanic rocks from the Itaiacoca Group: tectonic implications. Geologia USP: Série Científica, 3:39-49.

Souza A.P. 1990. Mapa geológico na escala 1:50.000 e esboşo da evoluşão tectônica e sedimentar do Grapo Itaiacosa, nas folhas Barra do Chapéu e Ouro Verde - SP/PR. Dissertação de Mestrado, IG/USP, 200 p.

Thedorovicz A., Câmara M.M., Morais S.M., Godoy H.K, Takahashi A.T. 1986. Projeto Engenheiro Maia-Ribeirão Branco. Relatório Final. CPRM/PROMINÉRIO. 3 vol.

Thedorovicz A., Câmara M.M., Takahashi A.T., Morais S.M., Godoy H.K. 1988. Geologia do Pré-Cambriano das folhas Engenheiro Maia e Ribeirão Branco, São Paulo. In: SBG, Cong. Bras. de Geol., 35. Ancis, 6:2713-2726.

Trein E., Reis Neto J.M. dos, Biondi J.C., Monastier M.S. 1985. Revisão da Formação Itaiacoca: identificação de uma sequência metavulcano-sedimentar em Abapã (PR). In: SBG, Simp. Reg. de Geologia, 5, Atas, 1:169-185.

Manuscrito A-1503

Recebido em 14 de abril de 2004 Revisão dos autores em 24 de maio de 2005 Revisão aceita em 16 de junho de 2005 